\title{
Long-Term Structural Health Monitoring of the Cleddau Bridge: Evaluation of Quasi-Static Temperature Effects on Bearing Movements
}

Rolands Kromanis*a, Prakash Kripakaran ${ }^{\mathrm{a}}$ and Bill Harvey ${ }^{\mathrm{b}}$

${ }^{a}$ College of Engineering, Mathematics and Physical Sciences, University of Exeter, Exeter, United Kingdom

${ }^{b}$ Bill Harvey Associates Ltd, Exeter, United Kingdom

*Corresponding author: rolands.kromanis@gmail.com 


\title{
Long-Term Structural Health Monitoring of the Cleddau Bridge: Evaluation of Quasi-Static Temperature Effects on Bearing Movements
}

\begin{abstract}
This paper illustrates how long-term measurements can be analysed to understand bridge behaviour under changing environmental conditions and how the developed understanding can help explain the performance of its critical components. Measurements from the Cleddau Bridge, a structure that has been continuously monitored for more than two years, are used to investigate thermal effects in steel box-girder bridges and, in particular, their bearings. Observed temperature distributions are very different to the recommended distributions in design codes (BS EN 1991-5:2003). These temperature distributions create plan bending of the box girder, which in turn impose forces at the bearings that have contributed to its wear. This paper investigates bearing movements of the bridge using numerical models, and estimates the resulting forces at the supports. A physics-based model of the bridge is created to which temperature distributions inferred from in-situ measurements are supplied as input. Model predictions are validated against measured deformations at the bearings. Subsequently the model is used to predict forces at the bearings due to plan bending and bearing locking. Results quantify the impact that thermal effects have on the performance of the bearings. They also highlight the significance of considering a range of temperature distribution scenarios that go beyond those given in the design codes in order to reliably evaluate thermal effects at the design stage.
\end{abstract}

Keywords: structural health monitoring, thermal response, continuous monitoring, roller-bearings, physics-based model

\section{Introduction}

Bridges are complex structures that form critical links in the transport infrastructure, and their uninterrupted operation is vital for the functioning of the economy and society. Permanent loss of bridges or even their temporary closure, for example due to damage suffered during extreme events or for unplanned maintenance, result in significant costs in the form of network disruption and losses to local businesses, and also cause 
frustration to their daily users. Consequently effective management of these assets is a major concern to bridge owners and operators. Currently assessments performed on the basis of subjective and often unreliable visual inspections largely determine the maintenance interventions undertaken on most bridges (Koh \& Dyke, 2007). The availability of robust and inexpensive sensing technologies however offers opportunities for moving to a new paradigm of bridge management that is based on assessment of full-scale structural performance using in-situ measurements (Omenzetter, Brownjohn, $\&$ Moyo, 2004). As a result, the number of bridges that are equipped with sensing systems has been steadily growing with recent developments in technologies for sensing, data acquisition, transmission and storage (Wenzel, 2009)

The research presented in this paper is aimed at illustrating how measurements collected from bridges by structural health monitoring (SHM) systems can be utilized to understand the performance of critical bridge components. SHM systems typically measure ambient and response parameters such as temperatures and displacements at regular time intervals for short- (e.g. days) or long-term (e.g. years). The quasi-static structural response measured by such systems is usually governed by slowly changing temperature variations, which follow diurnal and seasonal cycles (Kromanis \& Kripakaran, 2014). Prior studies in SHM have shown that deformations caused by seasonal temperature variations in long-span bridges could be as much as ten times the values induced by traffic (Catbas, Susoy, \& Frangopol, 2008). Consequently deformations and stresses induced by temperature variations can be a significant factor in determining the performance of various bridge components over time.

To account for the material expansion and contraction due to thermal effects, bridges are often equipped with bearings, which are mechanical elements that permit rotation and/or translation, at certain locations. Restraint of movements by 
malfunctioning bearings can result in stresses nearing or even exceeding design values in structural elements (Xu, Chen, \& Ng, 2010). In the long term, such effects may affect a bridge's performance, for example, by reducing fatigue life of its components. According to the Eurocodes BS EN 1990:2002 (British Standards Institution, 2005), the design working life of bridges is typically taken as 120 years while that for its bearings may be reduced to 50 years. While thermal actions and the increase of global air temperature due to climate change are noted as major factors for consideration in the design of bearings, the guidance on thermal actions given in Section 4 of BS EN 19911-5 (British Standards Institution, 2003) however offers only a few scenarios of temperature distributions that are related mostly to vertical temperature gradients.

Real-life bridges experience complex temperature distributions that can vary nonlinearly in all three spatial dimensions (Branco \& Mendes, 1993; Emanuel \& Taylor, 1985; Potgieter \& Gamble, 1989). For example, a bridge built across a valley or in an urban area with lots of tall buildings in its neighbourhood may have certain parts of its structure predominantly under shade while other parts are exposed directly to solar radiation. This can lead to complex transverse temperature gradients that vary depending on the time of day (Moorty \& Roeder, 1992). Since predicting all possible scenarios of temperature distributions that a bridge may experience is impossible at the design stage, designers typically employ a specific set of temperature scenarios that are representative of the extreme scenarios for the purpose of arriving at a feasible design. However, the in-situ performance of a bridge and its components depend to a large extent upon the actual traffic and environmental loads, and hence the best approach to track their real-time performance is by using field measurements (de Battista, Brownjohn, Tan, \& Koo, 2014; Xu et al., 2010). 
This study takes previous research forward by investigating how in-situ measurements of structural behaviour can help understand the performance of individual bridge components. The emphasis in this study is on examining the importance of thermal effects when evaluating the performance of bearings, specifically roller bearings. The aim is to illustrate the potential use of temperature and deformation monitoring data for

(i) assessing the performance and degradation of bearings, and

(ii) informing the design of bearing replacements.

The Cleddau Bridge, a steel-box girder bridge, which has been continuously monitored with temperature and displacement sensors since 2011, is used as a case study in this research. The wear and tear of its bearings that had been in service for around 40 years was accelerated by forces created by unique transverse temperature gradients across the bridge cross-section that were not considered comprehensively at the design stage. In order to understand the wear and tear process, a physics-based (PB) model of the bridge is created. Temperature measurements collected around the inner perimeter of the box girder are input as the only load to the PB model. Model predictions are used to compute displacements and forces at the bearings. The performance of the model is also assessed in terms of its ability to match measured bearing movements.

\section{The Cleddau Bridge}

The Cleddau Bridge (Figure 1) is located in South-West Wales. It was first opened to the public in 1975 . Being $819.4 \mathrm{~m}$ long, the seven-span steel box-girder bridge spans North to South between Pembroke Dock (at its North end) and Nyland (South end) across the estuary of the River Cleddau. This single carriageway bridge is at an elevation of $37 \mathrm{~m}$ above the maximum water level reached at high tides. The bridge had 
daily traffic of 12,300 vehicles in 2013 (Department for Transport, 2015), and has served more than 5 million vehicles since its construction in 1975.

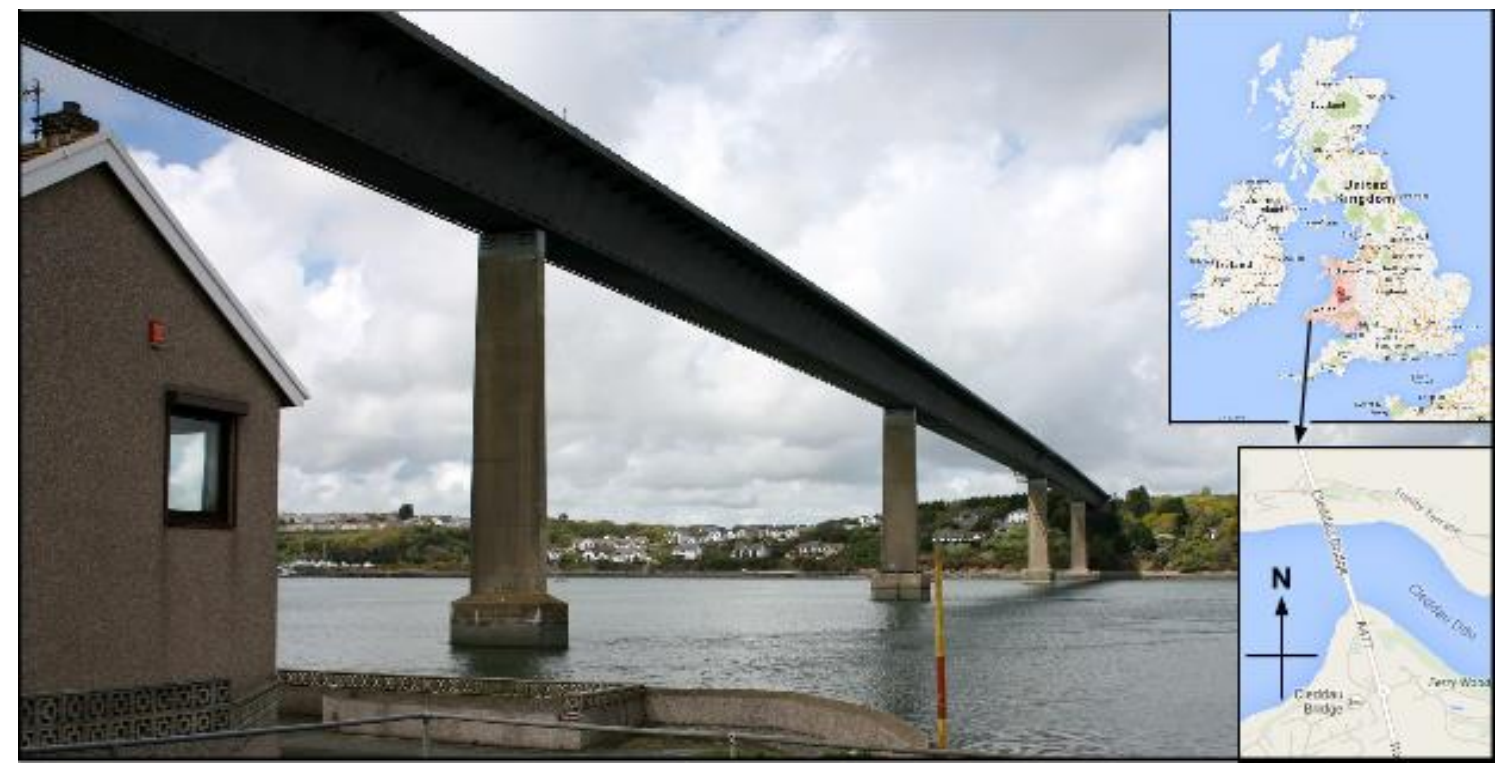

Figure 1. The Cleddau bridge (looking from east of Pembroke dock) (left) and its geographical location (right). (Courtesy: Pembrokeshire County Council)

A sketch with main dimensions of the bridge is shown in Figure 2. The bridge rests on six piers across the Cleddau River and on an abutment at each end. Each pier is designed as a fixed column; top ends of the piers are pinned to the bridge and the bottom ends fixed on bed-rock. Lengths of bridge spans range from $76.8 \mathrm{~m}$ to $213.4 \mathrm{~m}$. The longest span has a suspended portion that is hinged at its southern end via rocker bearings, and propped on two roller bearings at the northern end. A view of section A-A taken near the roller bearings is provided in the middle of Figure 2. The two roller bearings are from hereon referred to as east and west bearings according to which side they are on in relation to the vertical centre line shown in the section view. 


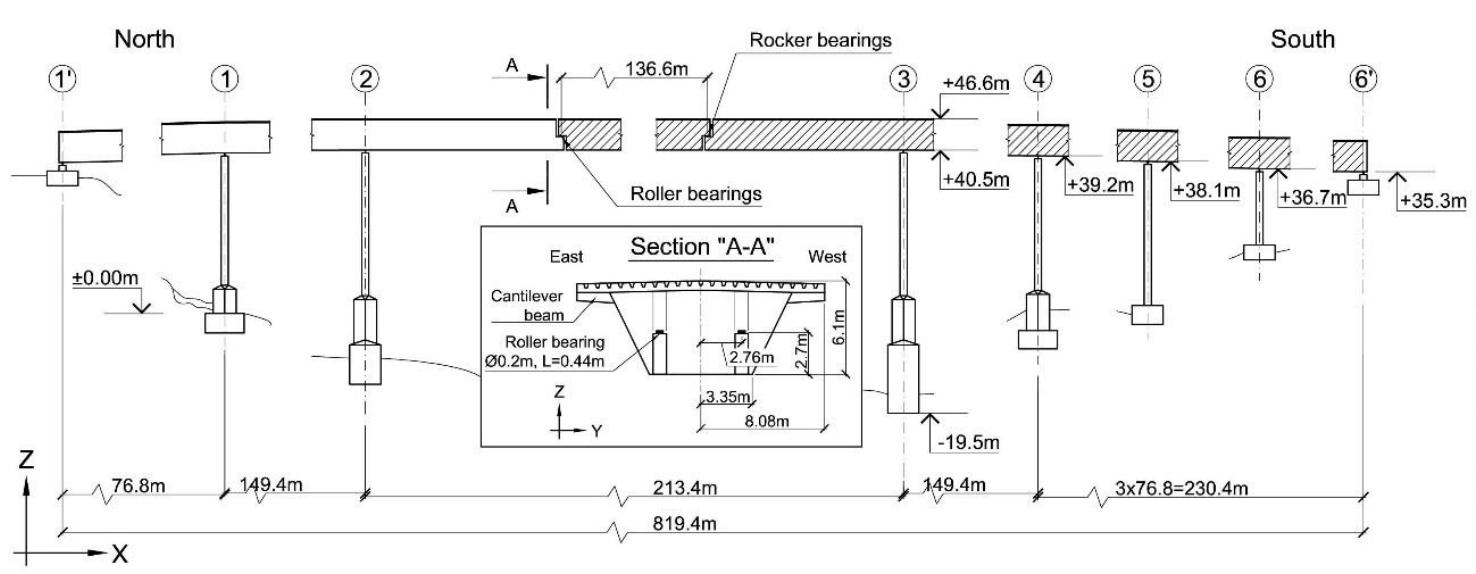

Figure 2. A sketch of the Cleddau Bridge; shaded portion of the bridge is modelled to investigate thermal effects.

As the bridge is aligned along the north-south axis, the east-facing and westfacing sides of the bridge are directly exposed to the sun during hours of sunrise and sunset respectively. This leads to strong temperature gradients in the transverse direction, i.e. across the box girder. The temperature differentials cause one side of the bridge to expand much more than the other and thereby create significant plan bending, i.e. bending about the vertical (direction of gravity) axis. The longitudinal and transverse temperature gradients in the bridge have a significant role in bearing movements and in turn, their degradation with time, as explained in the next section.

\subsection{Bearings}

The main function of a roller bearing is to eliminate undesirable forces and moments due to thermal expansion or contraction of material by freely allowing longitudinal movements. Partial or full restraint of this movement will exacerbate forces in the constrained section of the bridge and also introduce undesirable forces at the bearings. Each roller bearing is $440 \mathrm{~mm}$ long with a diameter of $203.2 \mathrm{~mm}$ (8”). Their centres are located at a height of $2.7 \mathrm{~m}$ from the bottom of the box-girder, and a horizontal distance of $2.76 \mathrm{~m}$ from the vertical central line of the box-girder (see Figure 2). The bearings are 
made of high strength steel. Sketches showing a view of a roller bearing from the east side, and a view across section a-a of the bearing are provided in Figure 3.
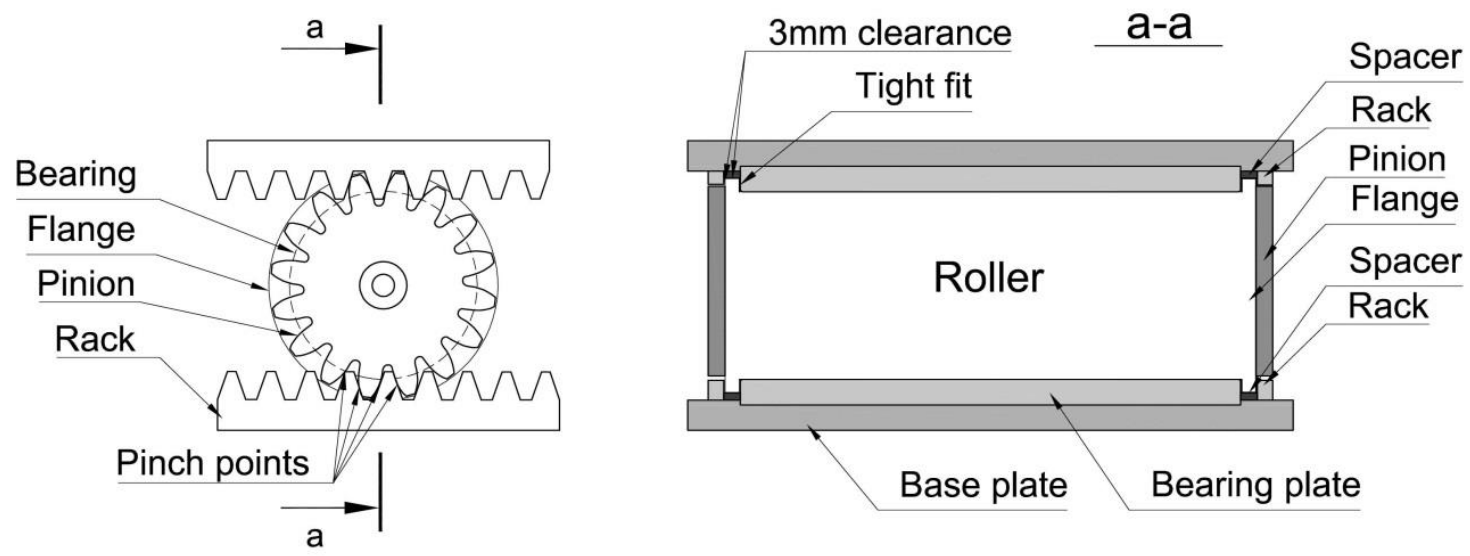

Figure 3. Bearing layout: a view from east side of the bridge of a roller bearing (left) and a section view of the bearing (right).

Both ends of the cylindrical bearings are formed into flanges that fit into the respective gaps between the bearing plates and the racks at either end (see Figure 3). To ensure unidirectional movement, a pinion is attached to each end of the bearing. Each pinion has two racks; one rack is attached to the suspended span and the other to the fixed span. These bearing components are designed to keep the main cylindrical portion of the bearings to be parallel to the Y-axis (Figure 2). Such a design implies that the bearings will offer resistance to plan bending of the box-girder, which results from the morning and evening sun causing significant temperature gradients across the width of the box-girder. Consequently, the forces arising from the bearings' resistance to plan twists are transferred to its flanges and the teeth of the pinions and racks. The repetitive application of such forces is considered to have been an important factor behind the deterioration of the bearings, which is discussed in detail in the next section. This premise is also corroborated by results from previous studies that have shown that stresses and deformations due to transverse temperature gradients, while often smaller 
in magnitude compared to those due to longitudinal temperature gradients, can pose a significant threat to structural performance (Moorty \& Roeder, 1992).

The study notes that the bearing design of the Cleddau Bridge is obsolete today, and that modern bridges are fitted with more sophisticated bearings that are designed to accommodate the kinds of movements discussed in the paper. However, a main motivation of this study is the fact that the in-situ maintenance and performance assessment of bearings continues to remain a challenge despite significant technological advances in the design and manufacture of bearings. This study aims to address this challenge by showing how measurements can support performance evaluation of bearings.

\section{Monitoring of the Cleddau Bridge}

Monitoring was initiated in October 2011 since bearings of the bridge, which had been in operation for nearly forty years, were visibly close to the end of their service life. Figure 4 shows the worn-out teeth of the pinion and rack at one end of a bearing at the commencement of monitoring. The hole in the pinion, which is centred on the main cylindrical axis of the bearing, has also been damaged as can be seen from Figure 4 (c). The bearings were vulnerable to corrosion from the accumulation of water during wet and cold seasons. Corrosion of a bearing and its rack are shown in Figure 5 (a). The forces on the bearings from plan bending are thought to have accelerated the deterioration process that may have been initiated by a lack of appropriate protection for the bearings from the harsh environment. A combination of the effects of corrosion, fatigue and excessive forces led to the fracture of a flange (see Figure 5 (b) and (c)), which in turn initiated the monitoring of the bearings. The monitoring was started initially to detect adverse behaviour of the bearings. It was then continued to understand 
their performance under operational and environmental loadings in order to inform the design of new replacement bearings, which were installed in May 2014.

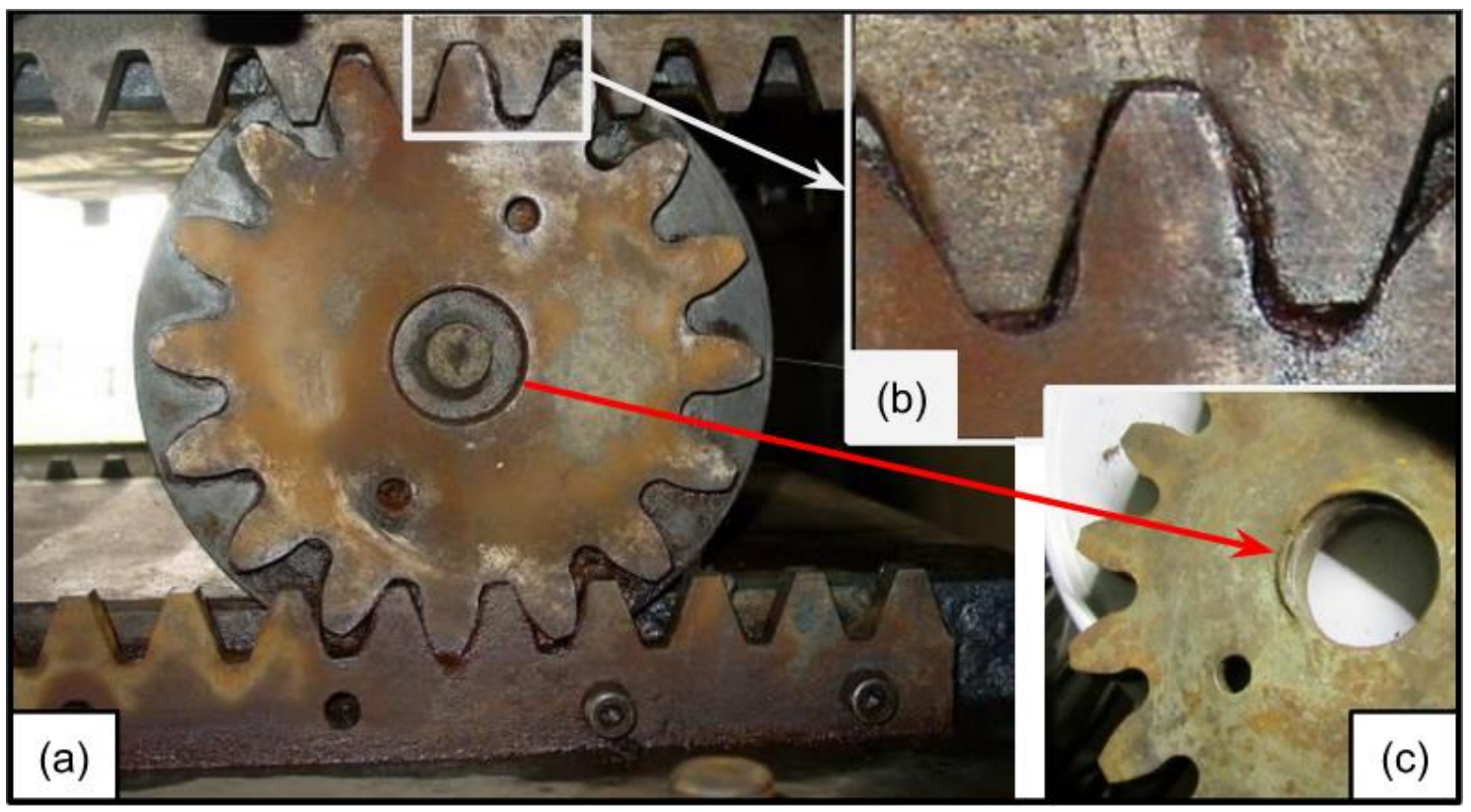

Figure 4. Damaged pinion: (a) front view, (b) closer look at worn out teeth and (c) central support. (Courtesy: Pembrokeshire County Council)

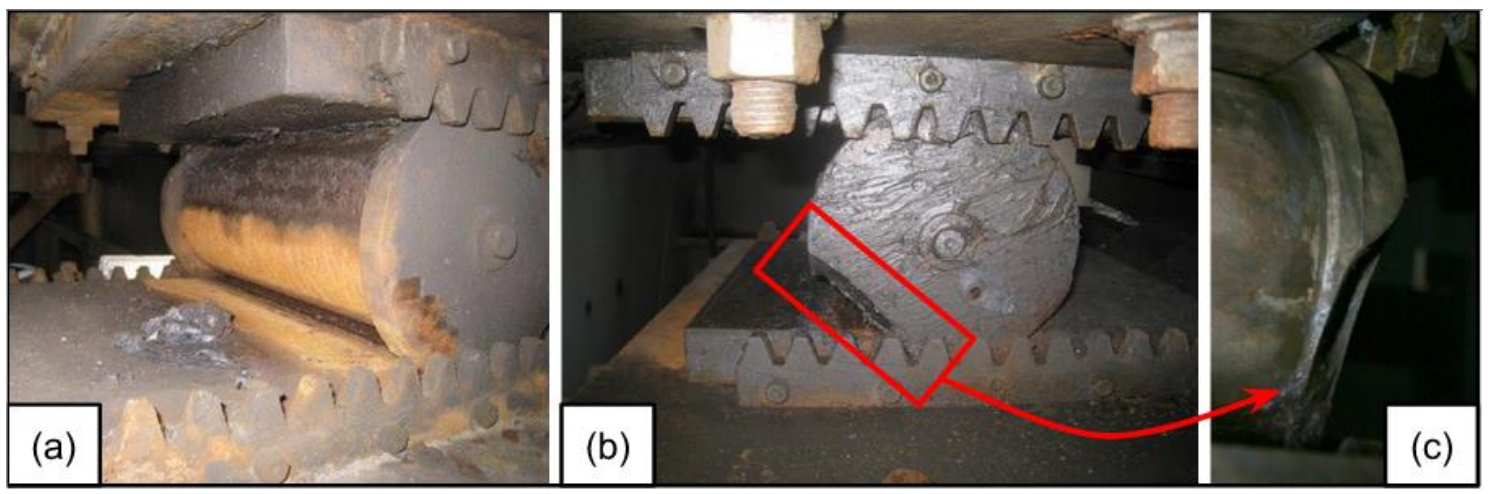

Figure 5. Damaged gears: (a) corrosion on a bearing and bearing plate, (b) and (c) damaged flange. (Courtesy: Pembrokeshire County Council)

\subsection{Monitoring system}

The monitoring system consists of a number of sensors for measuring temperatures and displacements. Twelve one-wire digital temperature sensors are installed a few meters away from the centre of the suspended section of the bridge. 
These are installed on the inside of the box-girder - three sensors on each of its faces, as shown in Figure 6 (left), to record surface temperatures every minute. Figure 6 (right) indicates the locations of sensors measuring structural displacements. Two linear potentiometers are connected to centre of the inner and outer faces of each bearing. Inner in this context refers to the bearing face that is closer to the vertical centre line of the girder. The potentiometers are setup to measure longitudinal movements at the two ends of each roller bearing. One string-pull potentiometer is installed at approximately $500 \mathrm{~mm}$ distance from the outer end of each bearing. These measure the gap between the suspended span and northern section of the bridge. These two measurements are further referred to as the "east gap" and "west gap" measurements.
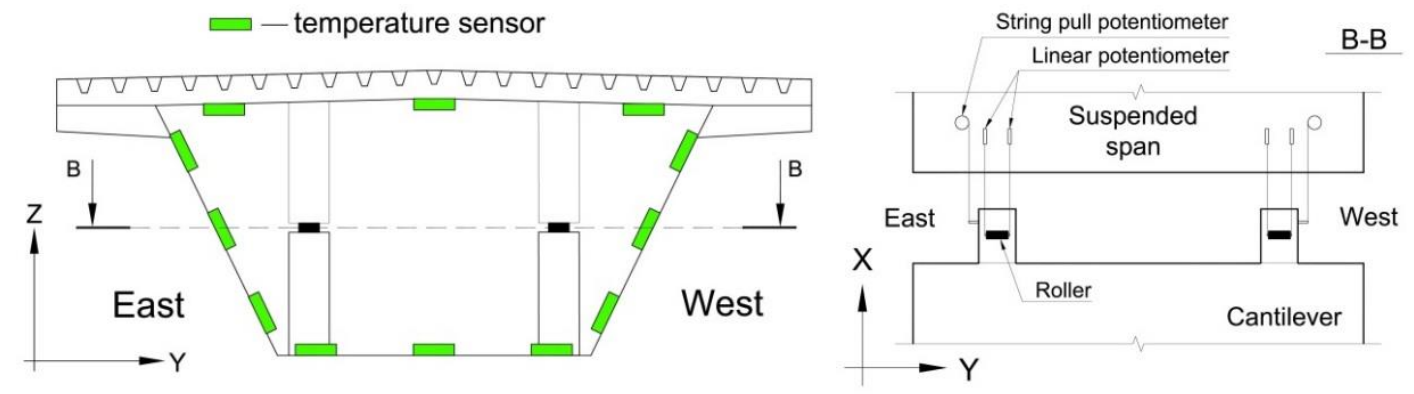

Figure 6. The location of one-wire digital temperature sensors (left) and displacement sensors (right).

The sensors measuring the gap and the movement at the outer end of east bearing are shown in Figure 7 (left). The connection of a sensor to a bearing after the removal of pinions is shown in Figure 7 (right). Bearing and gap displacements are collected at one-second intervals.

Analysis of the initial monitoring data indicated that the bearings twist and lock due to thermal effects. The pinions at the ends of the roller bearings were observed to be preventing the twist movements, and hence large forces were thought to be transferred across via the flanges of the bearings to the teeth of the pinions and eventually to the racks. These forces are likely to have caused the damage shown in Figure 4 and Figure 
5. The pinions and the racks were removed in order to release the twists of the bearings.

This research uses the data collected from the measurement campaign undertaken since the removal of the pinions and the racks.
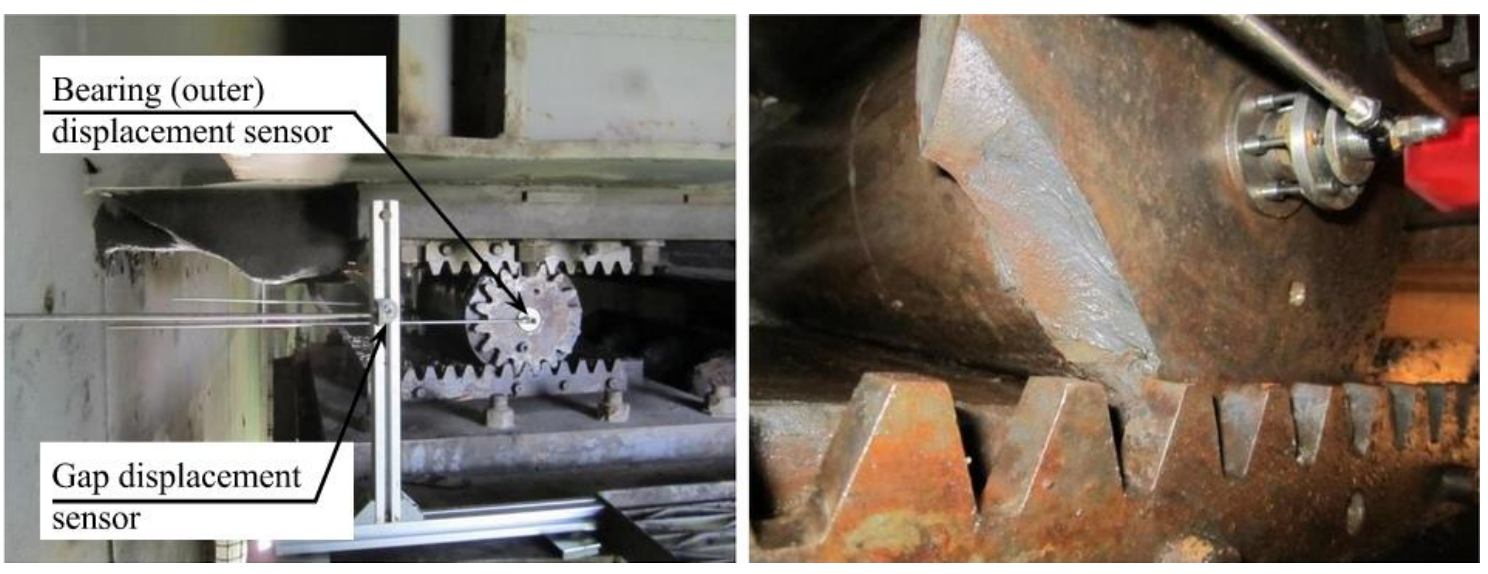

Figure 7. Instrumentation for measuring east bearing and east gap displacements (left) and sensor connection to a bearing (right). (Courtesy: Pembrokeshire County Council)

\subsection{Thermal and vehicular effects on bearing movements}

Figure 8 (left) shows temperature variations over two years collected with a temperature sensor on the top face of the box-girder. Measured temperatures reflect seasonal trends. Of interest to this study are the temperature variations produced across the girder crosssection. These variations can be understood by considering together the temperatures collected from all sensors (Figure 6). The measured temperatures from all sensors for three consecutive days in April 2013 are plotted in Figure 8 (right). This study focuses on these measurements as they produce an interesting combination of temperature gradients as discussed below.

- April 21 began cloudy but had sunshine during the latter half of the day. Consequently, temperatures do not vary much across the girder section during 
the morning, while, in the afternoon and evening, the temperature of its west face increases much rapidly relative to its other faces.

- April 22 was mostly cloudy. Hence differences between the maximum temperature, which is at the top face, and the minimum, which is at the bottom face, are small.

- April 23 was a sunny day. The temperature of the east face rises rapidly in the early morning hours and then drops later in the day. In contrast, temperatures of the top and west faces remain low during the early hours, and increase rapidly during the afternoon.

Of these three days, the temperature distribution for April 23 is particularly important from the perspective of this study. Variations of temperature across the width of the box-girder similar to that on April 23 can produce plan bending of the bridge, which then leads to plan twists at bearings as discussed later in this section.
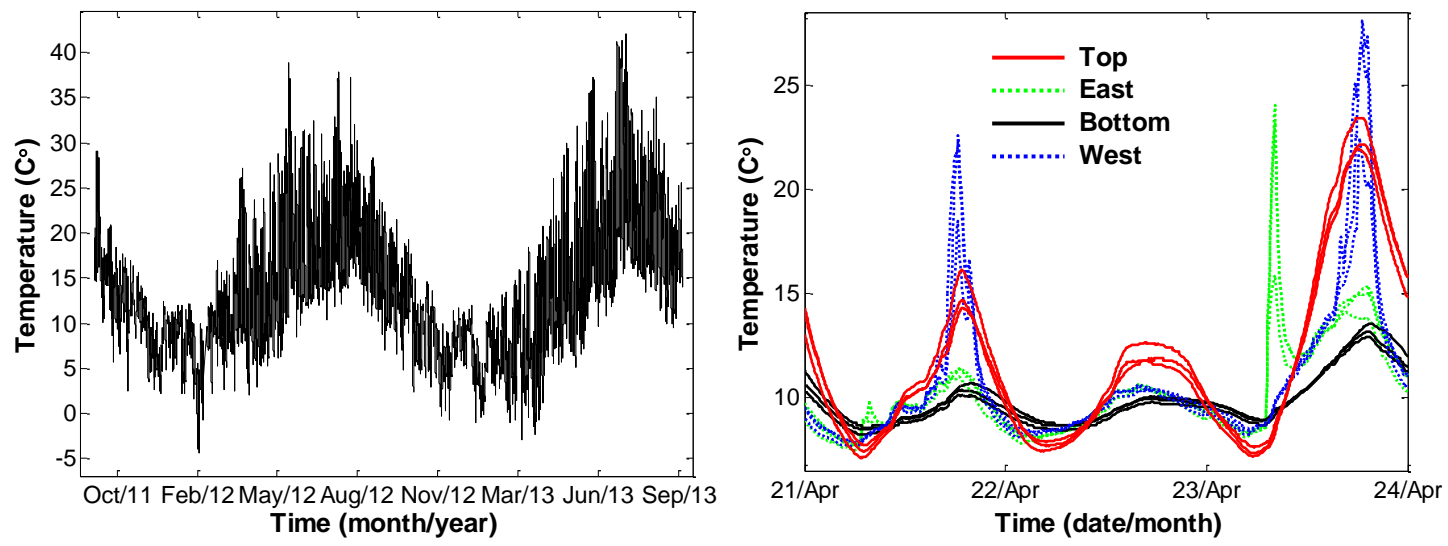

Figure 8. Temperature measurements from the top surface of the girder for two years (left) and time-histories of measurements from all twelve sensors over a three-day period (right).

Gap and bearing movements closely follow the temperature patterns. Figure 9 shows the time-history of east gap displacements for the chosen three days in April 
2013. A rise in temperatures in the early hours of April 23 results in a rapid expansion of the bridge, hence the size of the gap reduces proportionately.

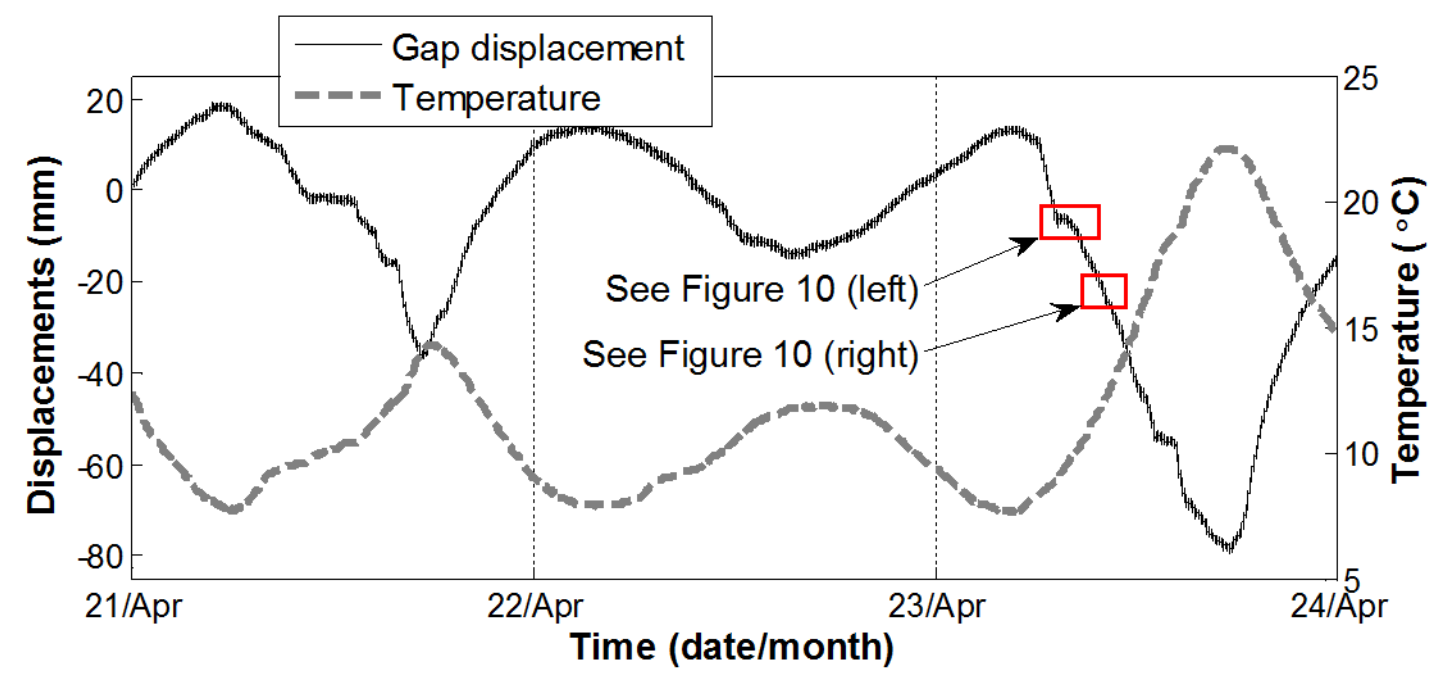

Figure 9. Variation in the measurement of the gap at the east bearing and the average of the temperatures measured by three temperature sensors on the top face of the boxgirder over a three-day period plotted in Figure 8 (right).

A car crossing the expansion joint does create a movement at the gap, although insignificant in comparison to those due to temperature variations. This movement can be masked by measurement noise or ambient vibrations. However, a heavier vehicle forces the gap to open more. This can be detected by having a closer look at the measurements (Figure 10). Smoothed time-histories of displacements are superimposed on measured displacements in Figure 10 (left) from which the effects of passage of a heavy vehicle on east-gap measurements are clearly discernible. In this case, the vehicle approaches the expansion joint from the left-hand side in Figure 2. When it approaches the pier at axis 2 (Figure 2), it forces the gap to close as the suspended portion is lifted upward. Once the vehicle crosses the pier and is on the cantilevered portion (Figure 2), it forces the gap to open up since the rollers are at a level below the neutral axis for the girder cross-section. As the vehicle reaches the gap, the joint is pushed downwards to the maximum thus enlarging the gap by approximately $2 \mathrm{~mm}$ (see Figure 10 ). 
Conversely, after the vehicle has crossed the expansion joint and approaches the pier at axis 3 (Figure 2), the size of the gap reduces. The size of the gap increases again after the vehicle crosses the pier. This effect of a heavy vehicle on bearing movements is reflected in the variation of the measured displacements as indicated in Figure 10. Vibrations due to the passage of a vehicle can last for many seconds after its passage. According to dynamic tests carried out by Eyre (Eyre, 1976), the Cleddau Bridge and particularly its $213 \mathrm{~m}$ long span have extremely low values for damping. Values for damping measured as an averaged form of logarithmic decrement were found to be between 0.0043 and 0.0061 at the structure's fundamental frequency of $0.53 \mathrm{~Hz}$. Consequently vehicle-induced movements may take up to a minute to fade.
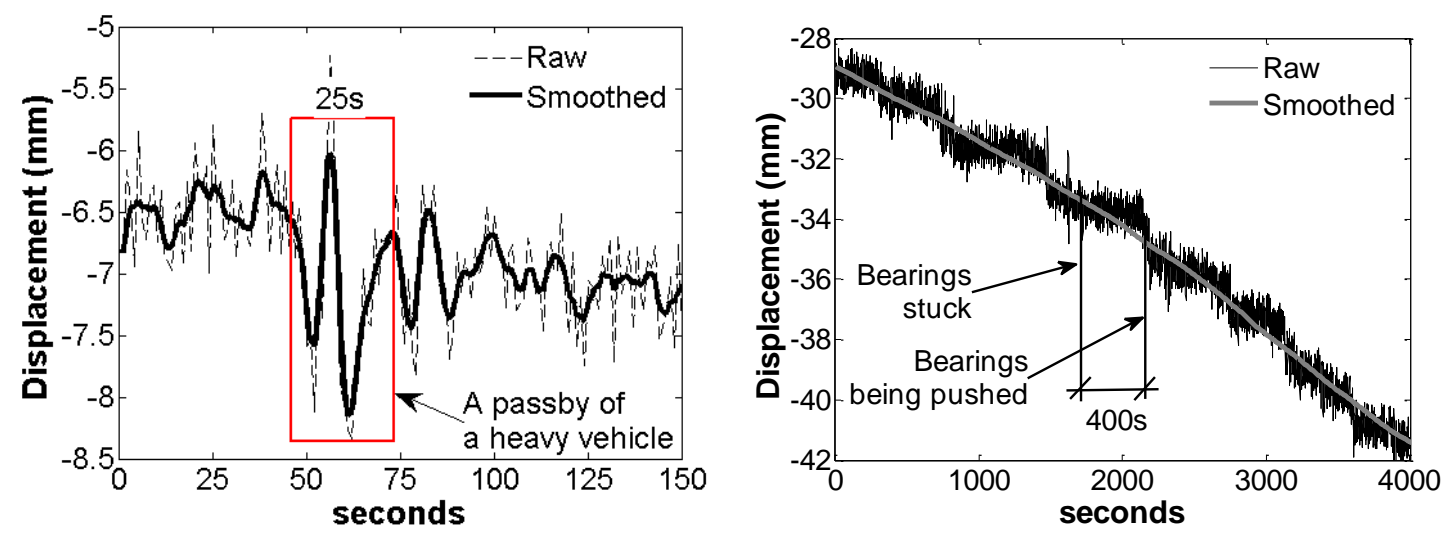

Figure 10. A closer look at east-gap measurements on April 23 in early morning (left) and measurements over a one-hour period showing bearing locking and release (right).

Time-histories of temperature measurements indicate that complex temperature distributions can be created in the bridge by diurnal variations in ambient conditions. In particular, transverse temperature gradients create plan bending and therefore plan twists at the bearings. The magnitude of the twists can be computed as the difference between the displacement measurements at the inner and outer ends of the bearings. Figure 11 (top) shows the time-history of the differences between raw measurements taken at the inner and outer ends of the west bearing. The figure plots results from measurements taken at a frequency of $1 \mathrm{~Hz}$. The data is extremely noisy making 
visualizing of trends difficult. Figure 11 (bottom-left) plots the same data as in Figure 11 (top) but after smoothing. While smoothing reduces the magnitudes of the peaks, the resulting plot is much sharper and also more useful for illustrating comparisons with predictions from numerical models. If there is no plan twist, the differences should be zero. However, the difference between measured movements of the inner and outer ends varies from around $-0.23 \mathrm{~mm}$ to $+0.23 \mathrm{~mm}$ in the smoothed data-set.

The mean distance travelled by a roller bearing is computed as the average of measured movements at its inner and outer ends. For April 23, values of this parameter for the west bearing are plotted against the difference between measured displacements at the inner and outer ends of the bearing in Figure 11 (right). The plot shows that the bearing moves about $60 \mathrm{~mm}$ over the course of a day primarily due to thermal effects. Note that this ignores vehicular effects as the bearing movements may have to be measured at a much higher sampling rate than 1 measurement per second to capture accurately the movements due to vehicular passage. On top of the longitudinal movements, the bearing also rotates in plan due to plan bending in a complex manner. Understanding the effects of plan bending in concert with those due to longitudinal movements is important to characterize bearing performance. 

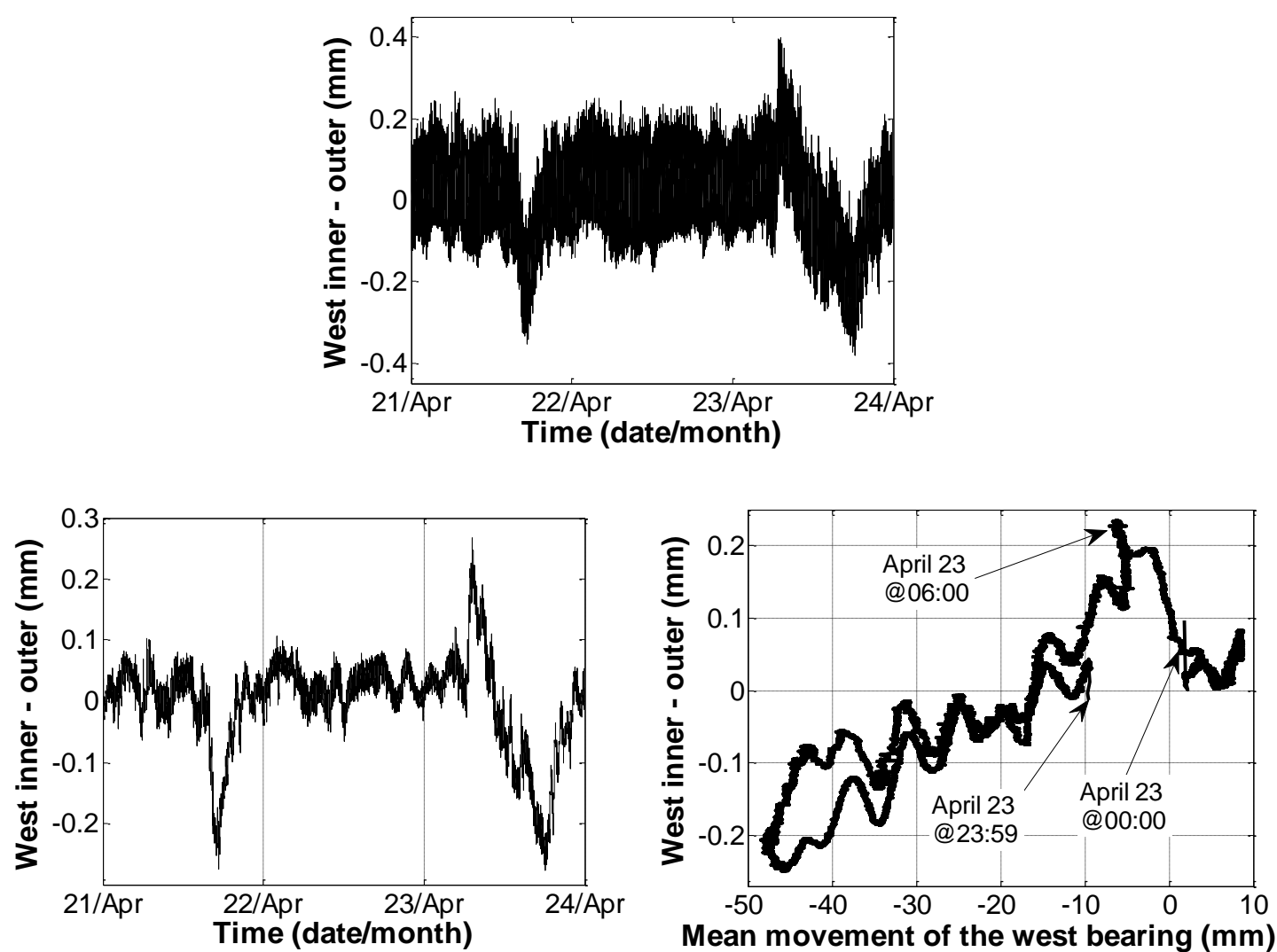

Figure 11. Raw (top) and smoothed (bottom left) time-histories of differences between the movements measured at the outer and inner ends of the west bearing; a graphical plot of the relationship between longitudinal movement and twist of the bearing over one day (bottom right).

\subsection{Bearing locking and release}

The frequency of measurement collection of bearing displacements is sufficiently high to reveal that bearing movements are seldom smooth (Figure 10). Movements happen incrementally and friction plays a significant role. Bearings are seen to lock briefly, and then release especially during periods when temperatures change rapidly. A certain slip force is required to initiate the release. This phenomenon has also been observed in previous research (Emerson, 1976). In Figure 10 (right), the abrupt drops in east-gap displacement that take place every 300 to 600 seconds are representative of this phenomenon. The slip force required to push bearings is determined later in this paper through the use of a PB model. 


\section{Structural Identification (St-Id)}

This section of the paper describes the approach used to interpret the collected measurements. The approach falls into a theme of SHM-related research called Structural Identification (St-Id), which refers to the application of system identification approaches (Ljung, 1998) to interpret measurements from monitoring. The aim is to develop analytical models that are capable of accurately predicting structural behaviour using measurements from SHM (Catbas, Kijewski-Correa, \& Aktan, 2011).

Techniques (Aktan \& Catbas, 2007) for St-Id differ in the level of physical information they require as input to their models. They can be broadly classified into the following two categories based on the types of models they employ:

1. Physics-Based (PB) models;

2. Non-Physics-Based (NPB) models.

Approaches that employ PB models are most common and these are often referred to as model-based approaches in literature. Model-based approaches employ one or more numerical models that have been developed considering the structure's material properties, geometry and boundary conditions. Creating PB models can be time and resource-intensive requiring expert knowledge of computational modelling (e.g. finite elements) (Goulet, Kripakaran, \& Smith, 2010). The accuracy of PB models can also be difficult to estimate as it depends upon modelling assumptions such as modelled geometry of structure, chosen behaviour model, inclusion of non-structural elements and choice of boundary conditions (Eamon \& Nowak, 2004). However, despite these drawbacks, PB models are essential for predicting quantities that cannot be measured directly such as stresses and forces in structural components.

In contrast to PB models, NPB models rely solely on measurements and require minimal structural knowledge. They are also typically less computationally-intensive 
that PB models. Consequently NPB models are often preferred over PB models for realtime measurement interpretation (Goulet \& Kiureghian, 2013). Approaches using NPB models attempt to detect anomalous structural behaviour by evaluating whether new measurements deviate sufficiently from those taken during a reference period when the structure is assumed to be in a healthy state. The emphasis in these approaches is on detecting a change in structural performance rather than in accurately predicting quantities related to structural performance. This study however aims to evaluate the forces created at bearings due to thermal effects, and therefore uses a PB model that incorporates knowledge of bridge behaviour.

The majority of SHM studies have employed a St-ID approach with a single PB model (Catbas et al., 2011), and these have focused primarily on the evaluation of modal parameters such as mode shapes, frequencies and damping from vibration-based monitoring (Brownjohn, 2007; Mehrjoo, Khaji, Moharrami, \& Bahreininejad, 2008; Xia, Chen, Weng, Ni, \& Xu, 2012). However, this study focuses on developing PB models using static measurements. Such approaches to St-Id have also been investigated previously (Sanayei, Imbaro, McClain, \& Brown, 1997; Sanayei \& Onipede, 1991). A few recent studies illustrating PB models for interpreting static measurements are mentioned here. Costa and Figueiras (2012) employed a FE model of Trezói Bridge (Marques \& Cunha, 2010), which is a metallic railway bridge in Portugal, to interpret measurements from its strain monitoring system. FE models of the Tamar Bridge (Westgate \& Brownjohn, 2011) in the UK and the Runyang (Wang, Li, \& Li, 2010) suspension bridge in China were calibrated with high accuracy using ambient vibration and static measurements. Most recently, Yarnold et al. (2015) introduced and evaluated an approach for temperature-based structural identification (TBSI) using an a priori FE model of the Tacony-Palmyra Bridge. Similar to the previously-mentioned studies, this 
research develops a FE model of the Cleddau Bridge using information of the as-built structure, and then validates the model using measurements of bearing movements. The unique aspect of this study is in the application of the developed model for predicting the forces at the bearings under various scenarios in order to support monitoring-based decision-making.

\subsection{Physics-based (PB) model}

In this study, a PB model of the bridge is created to evaluate and quantify thermal effects and their induced forces. Temperature is the only load applied to the model. Modelling all elements of the structure is difficult due to the complex geometry of the box girder section and the time required. Furthermore, temperature and deformation measurements are available only at a limited number of locations on the bridge. Thus only the main structural components, i.e. box girder elements are modelled. Four-node shell elements are used to model the girder. Its entire length from the portion supported on roller bearings to its southern end (see the hatched section in Figure 2) is represented in the model. The northern end of the suspended span of the bridge is supported at four nodes that are representative of roller bearings. The only boundary condition applied at these nodes is a constraint preventing movements in the vertical direction (Figure 12). The southern end of the suspended span is pinned at rocker bearings. This is modelled using nodes that allow rotations about all the three major axes (Figure 2) but no translational movements in the three major spatial directions. The girder is supported at the piers on the structural axes 3 to 6 (see Figure 2), and these girder-pier connections allow rotation and longitudinal movement of the girder. Diaphragms present across the box girder section at the supports are also modelled. 
Temperature time-histories are given as input at the nodes of the model.

Temperatures are assumed to be uniformly distributed along the length of the bridge and vary only in the transverse direction. This, while a simplification, is not a major concern in this study since (i) it is primarily concerned with plan bending of the bridge and, (ii) the bridge is aligned in the north-south direction and is in an open setting; hence, a part of the bridge span alone is unlikely to fall in shade. Temperature measurements are down-sampled to five-minute time steps, i.e. $3.3 \times 10^{-3} \mathrm{~Hz}$. After down-sampling, there are 864 measurement time steps in total over the selected period of three days. This saves computational time and does not affect results since only quasi-static effects are studied. As mentioned before, temperatures are recorded at three locations on each face of the box girder.

A sketch indicating the nodes and discretization for the girder cross-section in the numerical model is given in Figure 12. Temperature inputs to the various nodes are also indicated in this figure. T-1 denotes temperature from temperature sensor 1 on the top face of the girder. Similarly, B-i, E- $i$ and $\mathrm{W}-i$ indicate the measurements from sensor $i$ on the bottom, east and west faces respectively. Figure 12 shows that the deck is modelled using two layers of shell elements, while the side and bottom faces have a single layer of shell elements. The two layers of shell elements in the deck are interconnected by nine sets of vertical shell elements. 


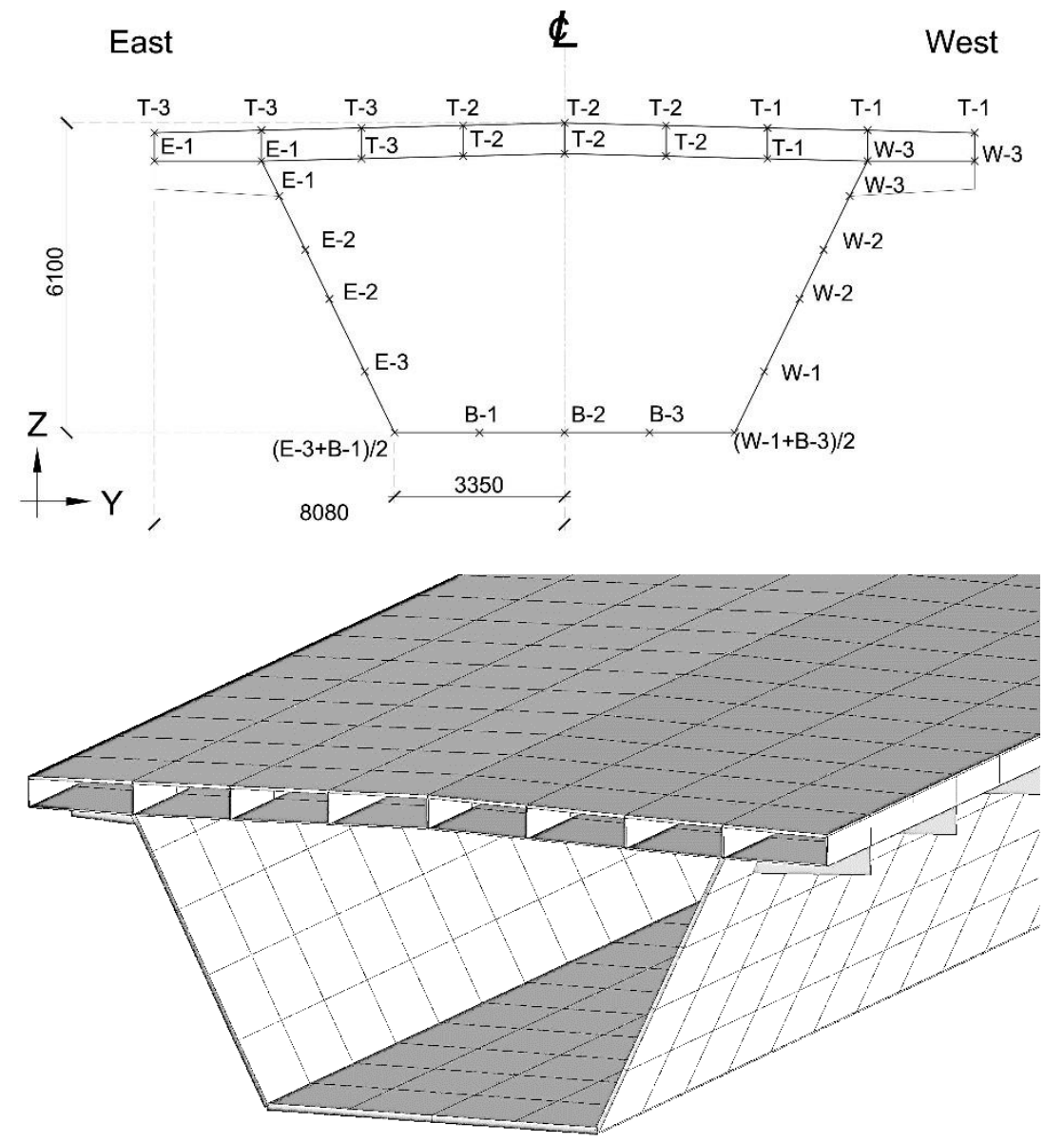

Figure 12. A sketch of the box-girder cross-section (top) indicating locations of nodes using crosses (x); a perspective view of the cross-section in the numerical model (bottom).

The PB model is created in ANSYS (ANSYS, 2011). The shell elements are modelled as made of structural steel with the following material properties: Poisson's ratio $v=0.3$, density $\rho=7850 \mathrm{~kg} / \mathrm{m} 3$, Young's modulus $E=200 \mathrm{GPa}$ and thermal expansion coefficient $\alpha=12 \times 10^{-6} \mathrm{~K}^{-1}$. The thickness of the top elements and web elements ranges from $10 \mathrm{~mm}$ to $30 \mathrm{~mm}$; thickness of bottom elements is $45 \mathrm{~mm}$; thickness of diaphragms and those elements adjacent to supports are $75 \mathrm{~mm}$. The total steel area of the cross-section of the box-girder as evaluated using these values for the thicknesses of the plates making up the box girder is close to the area of the section calculated from the structural drawings. 
A perspective view of the numerical model showing the elements forming the box girder is given in Figure 12. The view is of a section without a diaphragm. This figure shows the shell elements making up the box girder, and also the vertical shell elements used to model the stiffeners for the cantilevered portions of the deck. Figure 13 shows a sketch of the girder section at the bearings, where a diaphragm is present. The lighter solid lines represent the outline of the box girder that is visible in this view from behind the section at the bearings. A perspective view of the same girder section in the numerical model is shown in Figure 13.
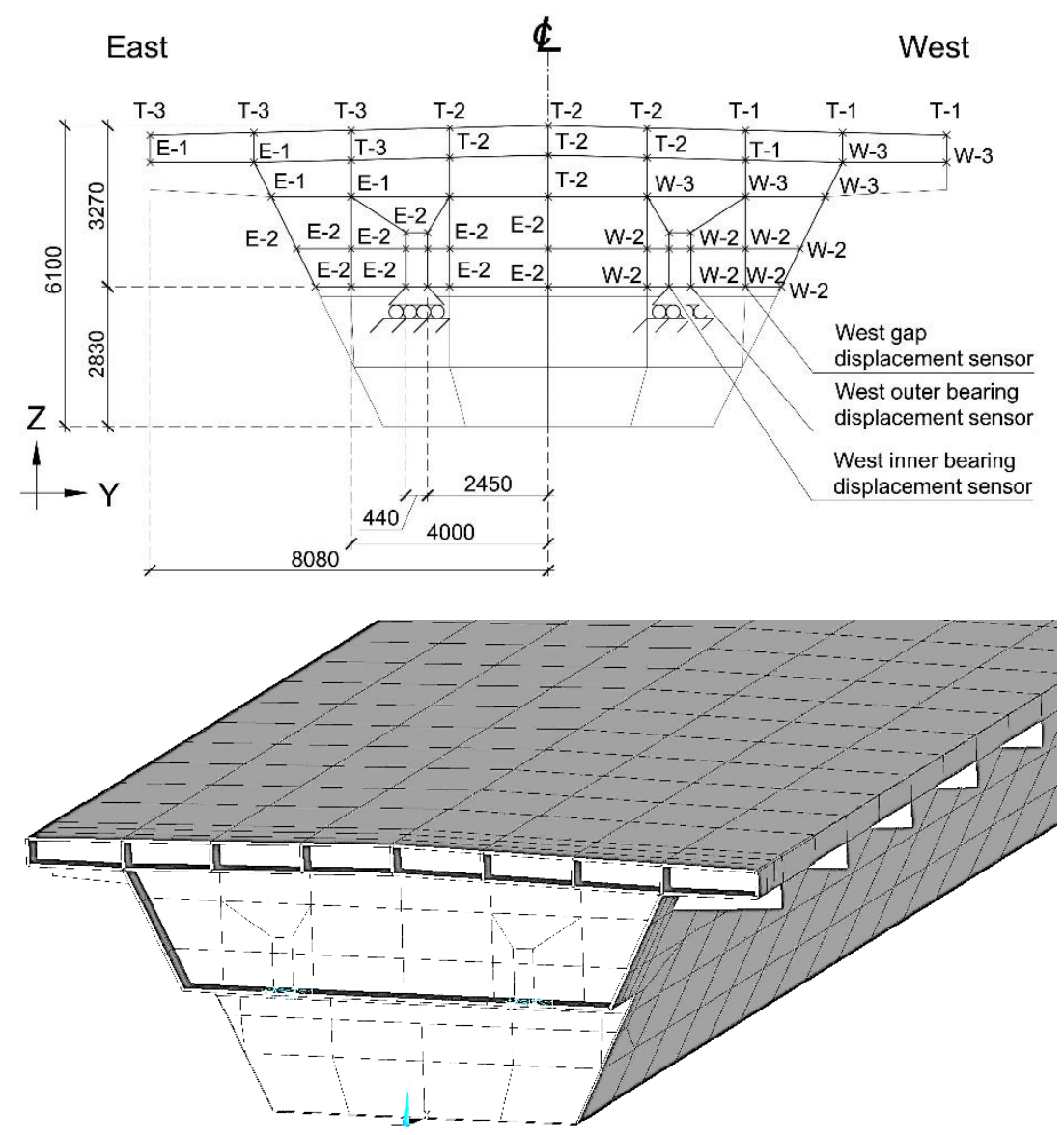

Figure 13. A sketch of the girder cross section at the two roller bearings (top), where there is a diaphragm present, with locations of nodes indicated by crosses (x); A perspective of the same section in the numerical model. 


\section{Evaluation of the PB model}

An FE solution of the PB model is given in Figure 14. It shows the deformed shape under thermal loads during the early hours of April 23, when the east face is exposed to steep temperature gradients. The transverse temperature gradients and the resulting plan bending of the box girder are evident from the figure.

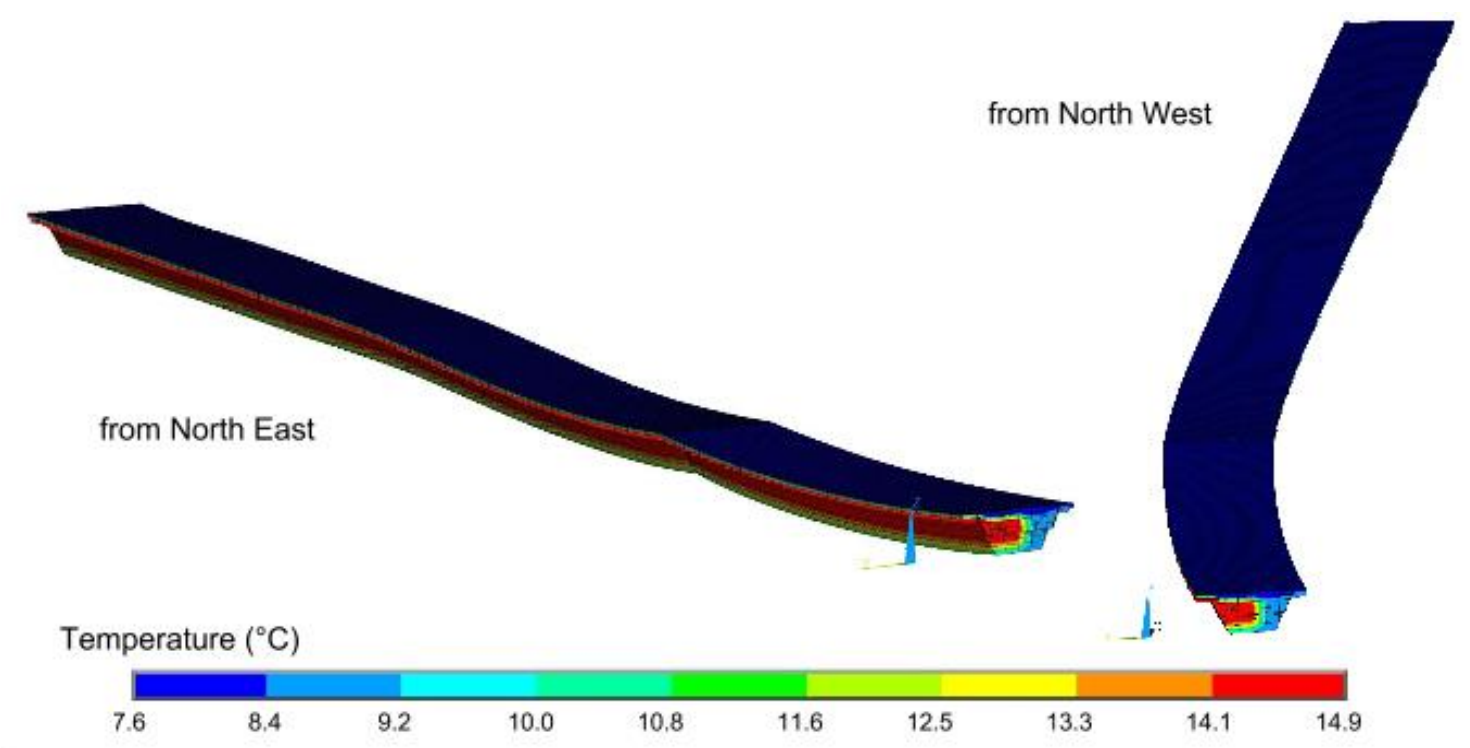

Figure 14. PB model of the bridge showing deformed structure and temperature distributions.

In the subsequent sections, the PB model is first validated by comparing computed displacements with measured values. Then the forces acting at the bearings are evaluated using the validated model.

\subsection{Bearing movements}

Displacement measurements of the gap and bearing movements are first smoothened, and the values at 5 minute intervals in the smoothened series are chosen to validate simulations. Figure 15 (left) corresponds to east-gap movements and Figure 15 (right) to movements at the outer end of the west bearing. These are simulated using measured 
temperatures (see Figure 8 (right)) for the selected three days (April 21 to April 24, 2012). Simulated movements are sufficiently accurate, especially when taking into account measurement and modelling uncertainties. It should be noted that while the model predicts movements of the bearing, measurements are of the gap between the suspended span and the northern part of the bridge. The northern part is however not included in the PB model (see Figure 2). Therefore the predicted movement of the roller bearing can only be indirectly related to the gap measurements. Figure 15 (right) shows that although the range of simulated movements at the west bearing is slightly larger than measured values, the trends have strong similarities. While a better match may be achieved by modelling the entire bridge, for the purposes of this study, the obtained bearing displacements and in particular, the displacement trends are sufficiently accurate to make predictions on bearing movements and forces.
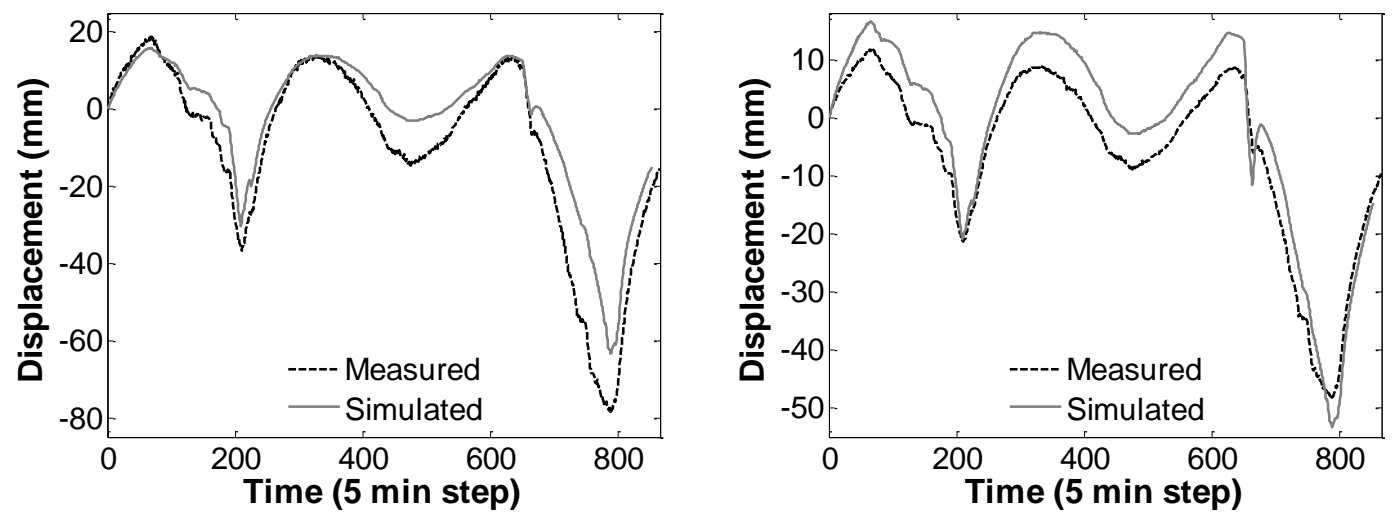

Figure 15. Measured and simulated time-series displacements of east gap (left) and the outer end of the west bearing (right) for three days.

Another important modelling uncertainty is the assumption that temperatures do not vary in the longitudinal direction of the bridge. As temperature measurements were available only at the mid-span cross-section of the box-girder, there is a lack of knowledge of the longitudinal temperature gradients. A better understanding of thermal loads would have been possible if temperature measurements were available also at the 
piers and at other sections along the box girder. This knowledge, when fed into the PB model, may give predictions that are closer to the measured bearing displacements.

Other modelling uncertainties include the use of a simplified structural model, possible errors in choice of material property values and ignoring contribution of non-structural elements such as pavement.

\subsection{Plan bending}

The roller bearings were designed to enable longitudinal translation and rotation. Assumptions on temperature distributions were that they would mainly cause longitudinal movements due to longitudinal and vertical temperature gradients, and possibly rotations due to vertical gradients along the depth of the bridge. However, as observed from the measurement-histories, the structure experiences transverse temperature gradients that lead to plan bending, which, in turn, causes plan twist of the bearings.

The plan twists are evaluated in terms of the differences between the measurements of the movements at the inner and outer ends of the bearings. Figure 16 (left) shows time-history of the measured and predicted plan twists. It plots measurements taken at one-second intervals while model predictions are at 5-minute intervals. Spikes in the plan twist time-history obtained from the PB model coincide temporally with measured values (Figure 16 (left)). However the magnitude is twice as large as the measured values. The large errors are partly due to modelling errors outlined in the Section 5.1, and the smoothing of the data-set discussed in Section 3.2 and illustrated in Figure 11. Measurements offer a more accurate representation of the movements, while model predictions are smoother due to using temperatures at 5- 
minute intervals. The large error between measurements and predictions can be attributed to the modelling errors mentioned in Section 5.1.

Simulated mean distance travelled by the west bearing is plotted against plan twists for April 23 in Figure 16 (right). As can be observed from the figure, the plan twist varies from around $-0.6 \mathrm{~mm}$ to $0.6 \mathrm{~mm}$. In the morning, the plan twist increases while the bearing is forced to also move in longitudinal direction. When the sun is no longer facing the east side of the bridge, this twist starts to reduce while the longitudinal movement is in the opposite direction. However it does not return on the same path because average temperature of the structure is still increasing. During the latter half of the day, movements in longitudinal and transverse directions mirror the movements in the morning (Figure 16 (right)). The west bearing moves a total of $70 \mathrm{~mm}$ over the course of a day. Even though plan twists are relatively small (of the order of $10^{\text {th }}$ of a $\mathrm{mm}$ ) in comparison, they can still impose significant forces at the bearings as shown later. The path of simulated movement and twist of the bearing (Figure 16 (right)) has some degree of similarity to the measured path (Figure 11). 

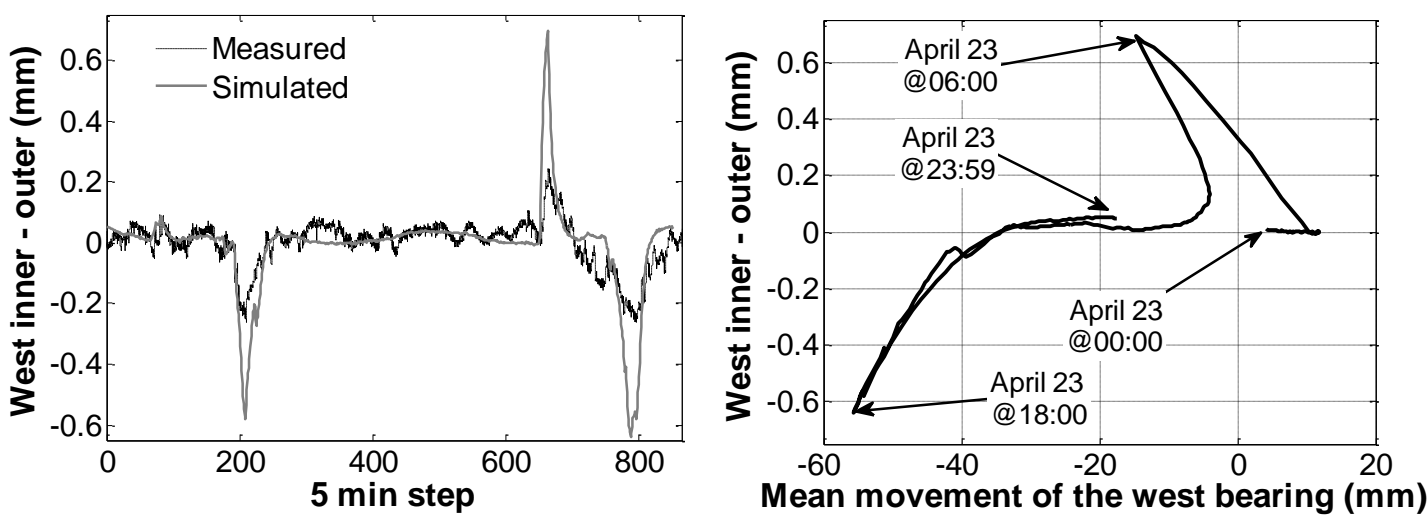

Figure 16. Measured and simulated time-histories of the difference between the movements at the outer and inner ends (i.e. plan twists) of the west bearing (left) and simulated movement and twist of the bearing (right).

\subsection{Bearing forces}

Simulated bearing movements are reasonably accurate as shown before and therefore derived bearing forces are also expected to be realistic. The interest in this study is in the transverse forces (in Y-direction (see Figure 2)) that are applied to the roller bearings when they are rotated in plan. Time-histories of transverse forces at the west bearing over the selected duration of measurements are plotted in Figure 17 (left). These forces are determined by restraining the relevant nodes in the model against movement in the transverse direction, i.e. y-direction in Figure 2. These forces reach magnitudes of over $2500 \mathrm{kN}$. Although these values are likely to be overestimates as the model has been shown to over-predict plan twists (see Figure 15), these are still indicative of the large forces imposed at the bearings when restraining plan twists. As the forces are applied in the transverse (along Y-axis) direction (see Figure 2), these pose a significant threat to the performance of bearings. Repeated application of such high forces could have exacerbated the effects of corrosion, and contributed to the damage observed in the flange of the bearing (Figure 5 (b) and (c)). As stated in Section 2.1, the bearings initially had pinions at each end (see Figure 4 (a)). They were designed to guide the 
bearing movement along the longitudinal direction of the bridge. Plan twists, however, were constrained by pinions. They were worn out by the repetitive longitudinal and twist movements over the years, and eventually the bearing was damaged.

This study then determines the forces required to release bearings locked in the longitudinal direction. Assuming that a bearing is completely locked, the force required to initiate the movement is the product of the weight of the structure and coefficient of sliding friction $(\mu) . \mu$ between steel and steel ranges from 0.15 to 0.6 (Cobb, 2008). In practice, bridge engineers assume $\mu=1 / 3$, which gives a friction force equal to $1 / 3$ of the weight of the structure. Assuming further that the force due to friction is the same at both bearings, they can be calculated as $2600 \mathrm{kN}$ at each bearing from knowledge of the weight of the structure.

The forces that are generated before the bearing is released can be determined if roller bearings of the PB model are restrained from movements in the longitudinal direction. The forces are predicted at the west bearing for the selected duration of monitoring, which is indicated in Figure 10 (right). Temperature measurements at a frequency of one measurement per minute are input to the PB model. While temperatures on all faces of the box-girder rise during the chosen period, temperatures applied on the top face of the girder are the highest. Therefore, it expands more than the others faces and, thus, the outer ends of bearings are pushed northwards and inner ends are pulled in the opposite direction. For this reason, the force at the inner end is small compared to that at the outer end for the chosen period. In this particular scenario, a resultant force of $100 \mathrm{kN}$ is generated at the west bearing due to it being locked for 400 seconds (see Figure 17 (right)). When the bearing is released, the force drops to zero, and then increases as the bearing is again locked in the longitudinal direction. As can be seen from the figure, for the next locking period, the slip force required is greater than 
$150 \mathrm{kN}$. The computed forces can be fed to a detailed numerical model of the bearing to understand the effect of these movements and forces on its wear and tear. This phenomenon of bearing locking and releasing must also be investigated in more detail over longer periods of time, and with collection of measurements at a higher frequency.
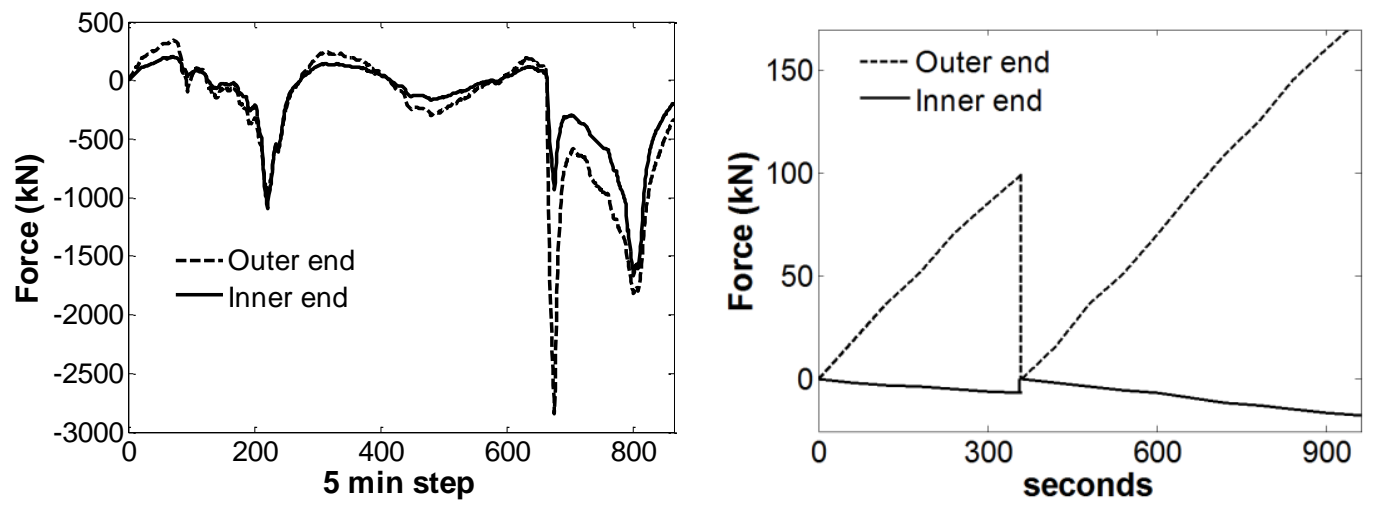

Figure 17. Forces at the west bearing induced by plan twists; these are in the horizontal plane and oriented transverse to the bridge girder (left). Forces at west bearing required to initiate translation after temporary locking (right).

\section{Discussion}

\subsection{Bearing movements}

Bearings are mechanical components of civil structures which cope with gradual and instantaneous movements generated by environmental effects (e.g. temperature and wind) and vehicular loadings. They are typically designed for a high tolerance $( \pm 0.5 \mathrm{~mm})$. However, evaluating all possible movements that bearings can undergo at their design stage can be difficult. For the Cleddau Bridge, the plan bending and its impacts on bearings were not foreseen fully. In addition to the thermal movements that were investigated in this study, forward-backward movements at the bearings of $0.3 \mathrm{~mm}$ caused by lateral vibrations, which are possibly from ambient conditions (e.g. wind), are also important (see Figure 18). Cumulative movements due to factors such as temperature and wind along with the effects of corrosion led eventually to degradation 
of the original roller bearings. These bearings were replaced in May 2014 by sliding bearings that were designed to permit sliding movements in the horizontal plane, and rocking movements in the $\mathrm{x}-\mathrm{z}$ plane (see Figure 2). Measurements collected from monitoring of the original bearings were used to decide on the range and magnitude of movements that the new bearings were required to support.

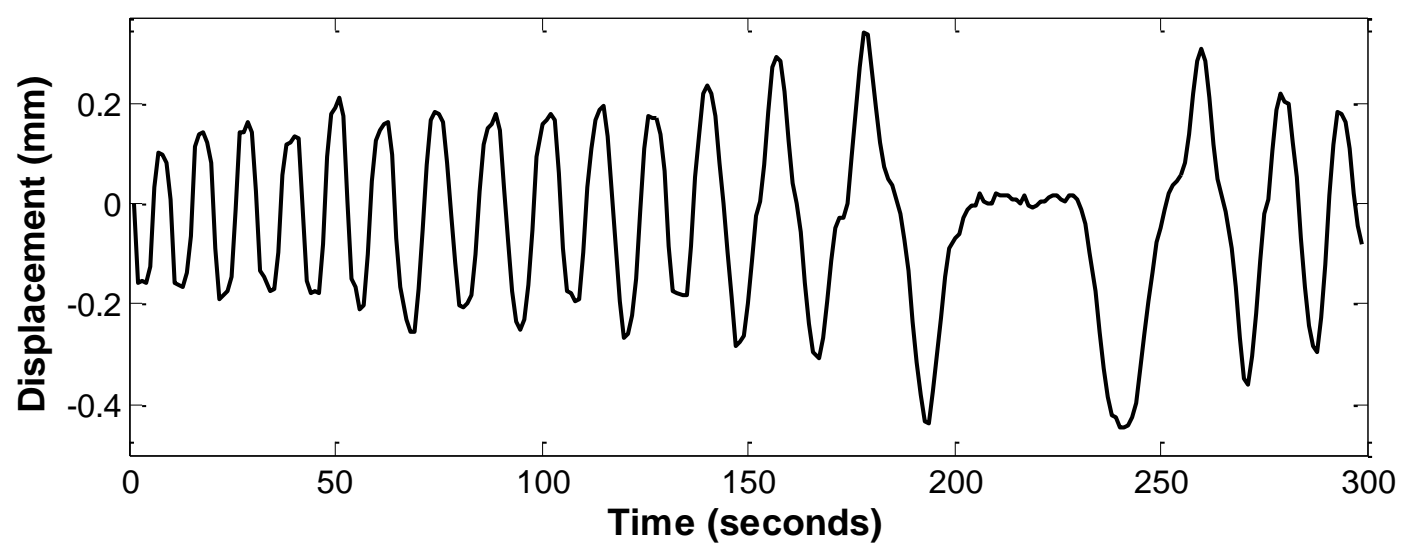

Figure 18. Lateral vibration: difference between measured displacements at the east and west gaps.

The wear and tear of bearings depends on the applied forces and the travelled distance of bearings. Total bearing movement $(l)$ over the selected days for simulation can be calculated by adding up distances (d) travelled between two measurement points. Equation (1) can be used to calculate the bearing movement.

$$
l=\sum_{i=2}^{m}\left|d_{i-1}-d_{i}\right|
$$

where $m$ is the number of measurements; $d_{i-1}$ and $d_{i}$ are the movements measured by the sensors at time-steps $i$ and $i-1$ respectively. Displacement measurements for the Cleddau Bridge were collected once per second. The total bearing movement over the selected three days and selecting measurements collected every second is $30.9 \mathrm{~m}$. Annual cumulative movements could be as much as $3800 \mathrm{~m}$. However, accurate measurements at a higher frequency may provide larger values for the daily and annual movement of 
the bearings. This aspect needs further investigation.

\subsection{Temperature distribution}

Temperature gradients according to Eurocodes are compared to those evaluated from collected measurements of the Cleddau Bridge in Figure 19. The gradients plotted for the bridge are obtained from the measured temperatures shown in Figure 8 (right). The Eurocodes BS EN 1991-1-5: 2003 (British Standards Institution, 2003) advise considering nonlinear temperature gradients for steel box-girders along the depth of the section at the design stage. The measured temperature gradients, although nonlinear as plotted in Figure 19, are however significantly different to the code-specified temperature distribution scenarios (heating/cooling). Therefore the scenarios given in the Eurocodes alone are insufficient to study the performance of the Cleddau Bridge. For this structure, temperatures vary not only along the depth of the box-girder but also along its breadth. The latter forces the bridge to bend in plan and creates twists in bearings. Transverse temperature gradients are also not captured accurately in the Eurocodes. For example, on a particular day (April 21, 2013), the difference in temperature between the east and west faces of the bridge girder was as much as $10^{\circ} \mathrm{C}$ (see Figure 8), almost double the $5^{\circ} \mathrm{C}$ difference suggested in the Eurocodes. These results highlight the significance of temperature effects on structural performance of bridges. More importantly, these results also show that performance assessment of bearings using temperature gradients given in the design codes can be unreliable. This is primarily because the codes were developed to help take into account the uncertainties in thermal variations during the design of a structure, while a structure's in-situ performance will depend actually upon the experienced daily and seasonal temperature variations. 


\begin{tabular}{|l|c|c|c|c|}
\hline \multirow{2}{*}{ Type of construction } & \multicolumn{4}{|c|}{ Temperature difference $(\Delta \mathrm{T})$} \\
\cline { 2 - 5 } & $\begin{array}{l}\text { According to the BS EN 1991-1-5: 2003, } \\
\text { Figure 6.2a - 1a. Steel deck on steel girder }\end{array}$ & \multicolumn{2}{c|}{ From the Cleddau bridge } \\
\hline Heating & Cooling & Morning April 23, 2012 \\
\hline \multirow{2}{*}{$\begin{array}{c}\mathrm{h} \text { - height } \\
\mathrm{T} \text { - reference temperature, } 0^{\circ}\end{array}$}
\end{tabular}

Figure 19. Temperature gradients recommended by the Eurocodes and measured from the Cleddau Bridge.

\section{Summary and conclusions}

Long-span bridges experience complex temperature distributions, and may therefore undergo deformations in ways that were not considered at the design stage. These deformations and the ensuing forces can have a significant effect on the performance and life of movement restraints such as bearings. This study, by using the Cleddau Bridge as a case study, shows that monitoring can help in characterizing bearing movements, and thereby assist with their maintenance and replacement. The following conclusions can be drawn from this study:

- Quasi-static structural response of bridges can be accurately estimated using distributed temperatures as the sole input loads to a PB model.

- Plan bending of the main box girder of the Cleddau Bridge generates plan twists at the roller bearings. These movements, which were not foreseen at the design stage, imposed large forces on the bearings and led to their degradation.

- Temperature distributions along the width (transverse) of box-girders can be an important factor determining bearing movements. This phenomenon needs to be more comprehensively considered in the codes of practice. 
Knowledge of temperature distributions when combined with an appropriate PB model can support performance evaluation of bridge bearings. PB models can also help in design and assessment of the effects of temperature increases due to climate change by utilizing predicted increases in average and peak temperatures (Klein Tank et al., 2002; Vuuren et al., 2008). Further work is however required in fully relating measurements from monitoring to the degradation and performance of bearings. This study has investigated only the effects of thermal loads. Effects of vehicles and wind loads also need to be evaluated. Furthermore, the PB model can also be employed to evaluate thermal effects on fatigue.

\section{Acknowledgment}

The authors would like to express their gratitude to Pembrokeshire County Council for providing access to the data from the Cleddau Bridge.

\section{References}

Aktan, A. E., \& Catbas, F. N. (2007). Long-term vision for the ASCE Technical Committee: Structural identification of constructed systems. In Proceedings of the 3rd International Conference on Structural Health Monitoring of Intelligent Infrastructure. Vancouver, British Columbia, Canada.

ANSYS. (2011). ANSYS® Academic Research, Release 14.0 .

Branco, F. A., \& Mendes, P. A. (1993). Thermal actions for concrete bridge design. Journal of Structural Engineering, 119(8), 2313-2331.

British Standards Institution. (2003). BS EN 1991-1-5: 2003: Eurocode 1: Actions on structures: General actions - Thermal actions. London.

British Standards Institution. (2005). EN 1990:2002+A1 2005: Eurocode: Basis of structural design (Vol. 1990).

Brownjohn, J. M. W. (2007). Structural health monitoring of civil infrastructure. Philosophical Transactions of the Royal Society a-Mathematical Physical and Engineering Sciences, 589-622. doi:DOI 10.1098/rsta.2006.1925 
Catbas, F. N., Kijewski-Correa, T., \& Aktan, A. E. (2011). Structural Identification( StId ) of Constructed Facilities Constructed Facilities. ASCE Publications.

Catbas, F. N., Susoy, M., \& Frangopol, D. M. (2008). Structural health monitoring and reliability estimation: Long span truss bridge application with environmental monitoring data. Engineering Structures, 30(9), 2347-2359.

Cobb, F. (2008). Structural engineer's pocket book (2nd ed.). Elsevier Ltd. Retrieved from http://books.google.com/books?hl=en\&lr=\&id=8jgEdD6pEkEC\&oi=fnd\&pg=PR1 $1 \& d q=$ Structural+Engineer\%E2\%80\%99s+Pocket+Book\&ots=VlcsfAKoyp\&sig= m4ofC15I1IB8g533Ro9H_hL03Qw

Costa, B. J. A., \& Figueiras, J. A. (2012). Evaluation of a strain monitoring system for existing steel railway . Journal of Constructional Steel Research, 72, 179-191.

De Battista, N., Brownjohn, J. M. W., Tan, H. P., \& Koo, K.-Y. (2014). Measuring and modelling the thermal performance of the Tamar Suspension Bridge using a wireless sensor network. Structure and Infrastructure Engineering, 1-18. doi:10.1080/15732479.2013.862727

Department for Transport. (2015). Annual Average Daily Flows. Retrieved from http://www.dft.gov.uk/traffic-counts/download.php

Eamon, C. D., \& Nowak, A. S. (2004). Effect of secondary elements on bridge structural system reliability considering moment capacity. Structural Safety, 26(1), 29-47. doi:10.1016/S0167-4730(03)00020-1

Emanuel, J. H., \& Taylor, C. M. (1985). Length-Thermal Stress Relations for Composite Bridges. Journal of Structural Engineering, 111(4), 788-804.

Emerson, M. (1976). Bridge temperatures estimated from the shade temperatures.

Eyre, R. (1976). Dynamic tests on the Cleddau bridge at Milford Haven.

Goulet, J. A., \& Kiureghian, A. Der. (2013). Forecasting anomalies using monitoring data and dynamic Bayesian networks. In The 6th International Conference on Structural Health Monitoring of Intelligent Infrastructure (pp. MS04-10). Hong Kong.

Goulet, J. A., Kripakaran, P., \& Smith, I. F. C. (2010). Multimodel Structural Performance Monitoring. Journal of Structural Engineering, 136(10), 1309-1318.

Klein Tank, A. M. G., Wijngaard, J. B., Können, G. P., Böhm, R., Demarée, G., Gocheva, A., ... Petrovic, P. (2002). Daily dataset of 20th-century surface air temperature and precipitation series for the European Climate Assessment. International Journal of Climatology, 22(12), 1441-1453. 
Koh, B. H., \& Dyke, S. J. (2007). Structural health monitoring for flexible bridge structures using correlation and sensitivity of modal data. Computers and Structures, 85(3-4), 117-130.

Kromanis, R., \& Kripakaran, P. (2014). Predicting thermal response of bridges using regression models derived from measurement histories. Computers and Structures, 136, 64-77.

Ljung, L. (1998). System identification. Birkhäuser Boston.

Marques, F., \& Cunha, Á. (2010). Evaluation of dynamic effects and fatigue assessment of a metallic railway bridge. Structure and Infrastructure Engineering, 6(5), 635646. Retrieved from http://www.tandfonline.com/doi/abs/10.1080/15732470903068904

Mehrjoo, M., Khaji, N., Moharrami, H., \& Bahreininejad, A. (2008). Damage detection of truss bridge joints using Artificial Neural Networks. Expert Systems with Applications, 35(3), 1122-1131.

Moorty, S., \& Roeder, C. W. (1992). Temperature dependent bridge movements. Journal of Structural Engineering, 118(4), 1090-1105.

Omenzetter, P., Brownjohn, J. M. W., \& Moyo, P. (2004). Identification of unusual events in multi-channel bridge monitoring data. Mechanical Systems and Signal Processing, 18(2), 409-430.

Potgieter, I. C., \& Gamble, W. L. (1989). Nonlinear Temperature Distributions in Bridges at Different Locations in the United States. PCI Journal, July-Augus, 80103.

Sanayei, M., Imbaro, G. R., McClain, J. A. S., \& Brown, L. C. (1997). Structural model updating using experimental static measurements. Journal of Structural Engineering, 123(6), 792-798.

Sanayei, M., \& Onipede, O. (1991). Damage assessment of structures using static test data. AIAA Journal, 29(7), 1174-1179. Retrieved from http://arc.aiaa.org/doi/abs/10.2514/3.10720

Vuuren, D. P. Van, Meinshausen, M., Joos, F., Strassmann, K. M., Smith, S. J., Wigley, T. M. L., ... Reilly, J. M. (2008). Temperature increase of 21 st century. Proceedings of the National Academy of Sciences, 105(40), 15258-15262.

Wang, H., Li, A., \& Li, J. (2010). Progressive finite element model calibration of a long-span suspension bridge based on ambient vibration and static measurements. Engineering Structures, 32(9), 2546-2556. doi:http://dx.doi.org/10.1016/j.engstruct.2010.04.028

Wenzel, H. (2009). Health Monitoring of Bridges (p. 621). Chichester: John Wiley \& Sons Ltd. 
Westgate, R., \& Brownjohn, J. (2011). Development of a Tamar Bridge finite element model. Dynamics of Bridges, 5, 13-20. Retrieved from

http://link.springer.com/chapter/10.1007/978-1-4419-9825-5_2

Xia, Y., Chen, B., Weng, S., Ni, Y. Q., \& Xu, Y. L. (2012). Temperature effect on vibration properties of civil structures: a literature review and case studies. Journal of Civil Structrual Health Monitoring, 2, 29-46.

$\mathrm{Xu}, \mathrm{Y} .$, Chen, B., \& Ng, C. (2010). Monitoring temperature effect on a long suspension bridge. Structural Control and Health Monitoring, 17(6), 632-653. doi:10.1002/stc

Yarnold, M. T., Moon, F. L., \& Aktan, A. E. (2015). Temperature-Based Structural Identification of Long-Span Bridges. Journal of Structural Engineering, 1-10. doi:10.1061/(ASCE)ST.1943-541X.0001270. 